\title{
Analysis of Differentially Expressed Long Noncoding RNA in Renal Ischemia-Reperfusion Injury
}

\author{
Fen Liu ${ }^{b}$ Yang Yang ${ }^{c}$ Tong Liu $^{a}$ Jun Deng ${ }^{a}$ Heng Zhang $^{a}$ Dan Luo ${ }^{a}$ \\ Yuan-Lei Lou ${ }^{a}$ \\ anstitute of Urology, The First Affiliated Hospital of Nanchang University, Nanchang, China; \\ ${ }^{b}$ Department of Critical Care Medicine, The First Affiliated Hospital of Nanchang University, \\ Nanchang, China; ${ }^{c}$ Department of Clinical Laboratory, Affiliated Stomatological Hospital of \\ Nanchang University, Nanchang, China
}

\section{Keywords}

Long noncoding RNA · Renal ischemia-reperfusion injury · RNA sequencing

\begin{abstract}
Background: Renal ischemia-reperfusion (IR) injury is one of the major causes of acute renal failure which seriously endangers the health and life of patients. Currently, there is still lack of comprehensive knowledge of the molecular mechanism of renal IR injury, and the regulatory role of long noncoding RNA (IncRNA) in renal IR damage remains poorly understood. Aim: The aim of this study was to analyze the expression spectrum of IncRNA in renal IR damage in mice and to explore specific IncRNA that may be involved in regulating the development of human renal IR injury. Methods: RNA-Seq was used to investigate the IncRNA profile of renal IR injury in a mouse model, and conservation analysis was performed on mouse IncRNAs with differential expression (fragments per kilobase of transcript per million mapped reads $\geq 2$ ) by BLASTN. The potential functions and associated pathways of the differentially expressed IncRNA were explored by bioinformatics analysis. The cell hypoxia model was used to detect the expression of the candidate IncRNA. Results: Of the 45,923 IncRNA transcripts detected in the samples, and 5,868 IncRNAs were found to be significantly differentially expressed ( $p<0.05$ and fold change $\geq 2$ ) in 24-h IR kidney tissue compared to the expression in the control group. It was found that 56 differently expressed mouse IncRNA transcripts have human homology by analyzing the conserved sequences. We also found that IncRNANONHSAT183385.1 expression significantly increased in HK2 cells after $24 \mathrm{~h}$ of hypoxia and
\end{abstract}

F. Liu and Y. Yang contributed equally to this work. 


\section{Kidney \\ Blood Pressure \\ Research}

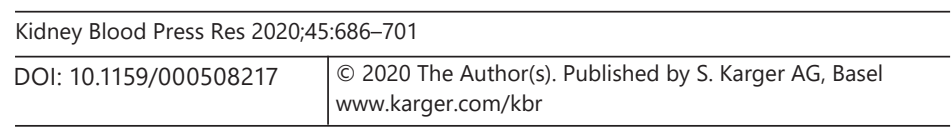

Liu et al.: Differentially Expressed IncRNA in Renal Ischemia-Reperfusion Injury

increased further $6 \mathrm{~h}$ after reoxygenation, and after $24 \mathrm{~h}$ of reoxygenation it was dramatically downregulated, indicating that NONHSAT183385.1 may be involved in the pathophysiological process of renal tubular epithelial cells in response to ischemia in human renal IR. Conclusion: Our study revealed differentially expressed IncRNAs in renal IR damage in mice and identified a set of conserved IncRNAs, which would help to explore IncRNAs that may play important regulatory roles in human renal IR injury.

(C) 2020 The Author(s)

Published by S. Karger AG, Basel

\section{Introduction}

Renal ischemia-reperfusion (IR) injury is a clinically common and complicated pathophysiological event with a high incidence and mortality rate. A violent surge in reactive oxygen, excessive release of inflammatory mediators, massive infiltration of neutrophils, cellular calcium overload, and mitochondrial dysfunction are pivotal elements leading to renal functional cell damage [1-3]. So far, the detailed molecular mechanism of the progression of renal IR injury has not been fully understood, and effective clinical therapies are still lacking. Although much progress has been made in the research of the function of proteincoding genes in renal IR injury, the specific regulatory mechanisms leading to the development and progression of renal IR damage remain unclear. Long noncoding RNAs (lncRNAs) are a class of transcripts that are longer than 200 nucleotides, with little coding capacity for proteins [4-7]. IncRNAs are classified as intergenic, antisense, sense overlapping, bidirectional, and intronic IncRNA according to the genomic location with respect to adjacent proteincoding genes [8] and interfere with gene expression in multiple ways [9-11]. Recent studies have shown that lncRNA plays a key regulatory role in diverse biological processes such as cell cycle, proliferation, differentiation, apoptosis, and metabolism [12,13]. Regulation of IncRNA is necessary to maintain tissue homeostasis, and its dysregulation contributes to human disease [14-17]. It has been reported that IncRNAs are involved in various kidney diseases [18-20]. However, their specific role in the physiopathology of renal IR injury is still largely unknown. Here, we investigated the expression patterns of IncRNA after $24 \mathrm{~h}$ of renal IR by RNA sequencing using a mouse model, aiming to better understand the gene regulatory rules of renal IR injury in humans. In addition, we performed a conservative analysis of differently expressed IncRNAs in renal IR lesions of the mouse with human IncRNAs, which will help to further reveal IncRNAs that may play key roles in the regulation of human renal IR damage.

\section{Materials and Methods}

\section{Renal IR Injury Model}

To investigate the involvement of IncRNA in kidney tissue injured by IR, we induced renal IR injury in mice. Experiments were performed on adult male C57BL/6 mice (6-8 weeks old and weighing 20-25 g) purchased from the Second Military Medical University of China. Animals were maintained under conditions free of specific pathogens. Induction of renal IR injury was performed as described previously [21]. Briefly, mice were intraperitoneally anesthetized with $4 \%$ chloral hydrate $(10 \mu \mathrm{L} / \mathrm{g})$. The kidneys were exposed by abdominal incision and the right kidney was removed following ligation of the right ureter. The left renal pedicle was clamped completely for 45 min using a microvascular clamp. Mice were kept well hydrated with warm saline and a homoeothermic station to maintain body temperature at $37^{\circ} \mathrm{C}$. Sham control animals were subjected to the same procedure without left renal pedicle 


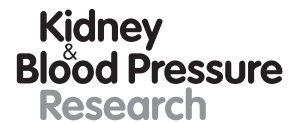

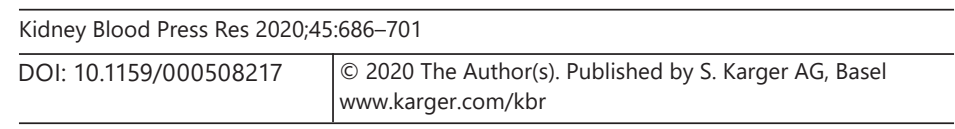

Liu et al.: Differentially Expressed IncRNA in Renal Ischemia-Reperfusion Injury

clamping. Mice were sacrificed $24 \mathrm{~h}$ after reperfusion. Blood samples were collected at the same time for biochemical analyses, and the left kidneys harvested were cut in half longitudinally. Half of each kidney was either snap-frozen in liquid nitrogen and stored at $-80^{\circ} \mathrm{C}$ for subsequent transcriptome sequencing and quantitative real-time PCR (qRT-PCR) analysis or perfusion-fixed with $4 \%$ paraformaldehyde for histological analysis.

\section{Serum Biochemical Parameters and Histological Examination}

Serum creatinine and blood urea nitrogen concentrations were measured using a 7180 Automatic Analyzer (Hitachi, Japan) to assess renal function. Kidney tissue samples fixed in $4 \%$ paraformaldehyde were embedded in paraffin and stained with hematoxylin and eosin for histological analysis of tubular injury.

\section{RNA Extraction, Library Preparation, and Next-Generation Sequencing}

Total RNA was isolated from renal tissue using RNAiso Plus Total RNA extraction reagent (Takara) following the manufacturer's directions. RNA was qualitatively and quantitatively analyzed using a NanoDrop ND-2000 spectrophotometer and checked for a RIN number to inspect RNA integrity by an Agilent Bioanalyzer 2100 (Agilent). Qualified total RNA was further purified by RNAClean XP Kit (Beckman) and RNase-Free DNase Set (QIAGEN). The Shanghai Biotechnology Corporation constructed the RNA-Seq libraries and performed the high-throughput sequencing on the Illumina HiSeq 2500 system (Illumina) using paired-end technology.

\section{Prediction of Conserved IncRNAs}

Most lncRNAs display a low conservative property of sequence between humans and mice. In order to investigate the possible regulatory role of IncRNA in human renal tissue after IR injury, we used BLASTN to make a conservative evaluation of candidate mouse IncRNAs with differential expression. To facilitate further study, these differentially expressed IncRNA transcripts were selected by filtering on the basis of the following parameters: (1) fragments per kilobase of transcript per million mapped reads (FPKM) $\geq 2$ in either control or IR treatment groups, and (2) differential expression of the target gene. Those lncRNAs with the best high degree of similarity ( $E$ value $\leq 10^{-5}$ ) in bidirectional comparison were considered as potential orthologs.

\section{Cell Culture and Hypoxia}

HK2 cells were maintained in DMEM/F12 supplemented with $10 \%$ fetal bovine serum (Bioind) at $37^{\circ} \mathrm{C}$ with $5 \% \mathrm{CO}_{2}$. For hypoxia-reoxygenation, cells cultured in serum-free medium for $24 \mathrm{~h}$ were placed in a hypoxia incubator (Sanyo, Japan) under anoxic conditions at $5 \% \mathrm{CO}_{2}, 94 \% \mathrm{~N}_{2}$, and $1 \% \mathrm{O}_{2}$ for $24 \mathrm{~h}$ followed by normoxic culture for 3,6 , and $24 \mathrm{~h}$. Cells cultured under normoxic conditions were used as control and hypoxia-treated cells confirmed by immunoblot analysis for hypoxia-inducible factor $1 \alpha$.

\section{Quantitative Real-Time PCR}

IncRNAs were randomly selected to perform qRT-PCR validation. Total RNA of HK2 cell was isolated as described above. cDNA was synthesized from $1 \mu \mathrm{g}$ of total RNA per sample using a Thermo Fisher Scientific ${ }^{\mathrm{TM}}$ RevertAid First-Strand cDNA Synthesis kit (Thermo Fisher Scientific, Inc.). qRT-PCR was performed on an Applied Biosystems ViiA ${ }^{\mathrm{TM}} 7$ Dx (Thermo Fisher Scientific, Inc.) in a total volume of $10 \mu \mathrm{L}$ using the SYBR-Green PCR mix (Thermo Fisher Scientific, Inc.). Primers designed using the Primer Express 3.0 software are presented in Table 1. The PCR reaction conditions were as follows: denaturation at $95^{\circ} \mathrm{C}$ for $5 \mathrm{~s}$, followed by 40 cycles at $95^{\circ} \mathrm{C}$ for $10 \mathrm{~s}$ and $60^{\circ} \mathrm{C}$ for $30 \mathrm{~s}$. All amplification reactions were carried out 
Table 1. Quantitative real-time PCR primers

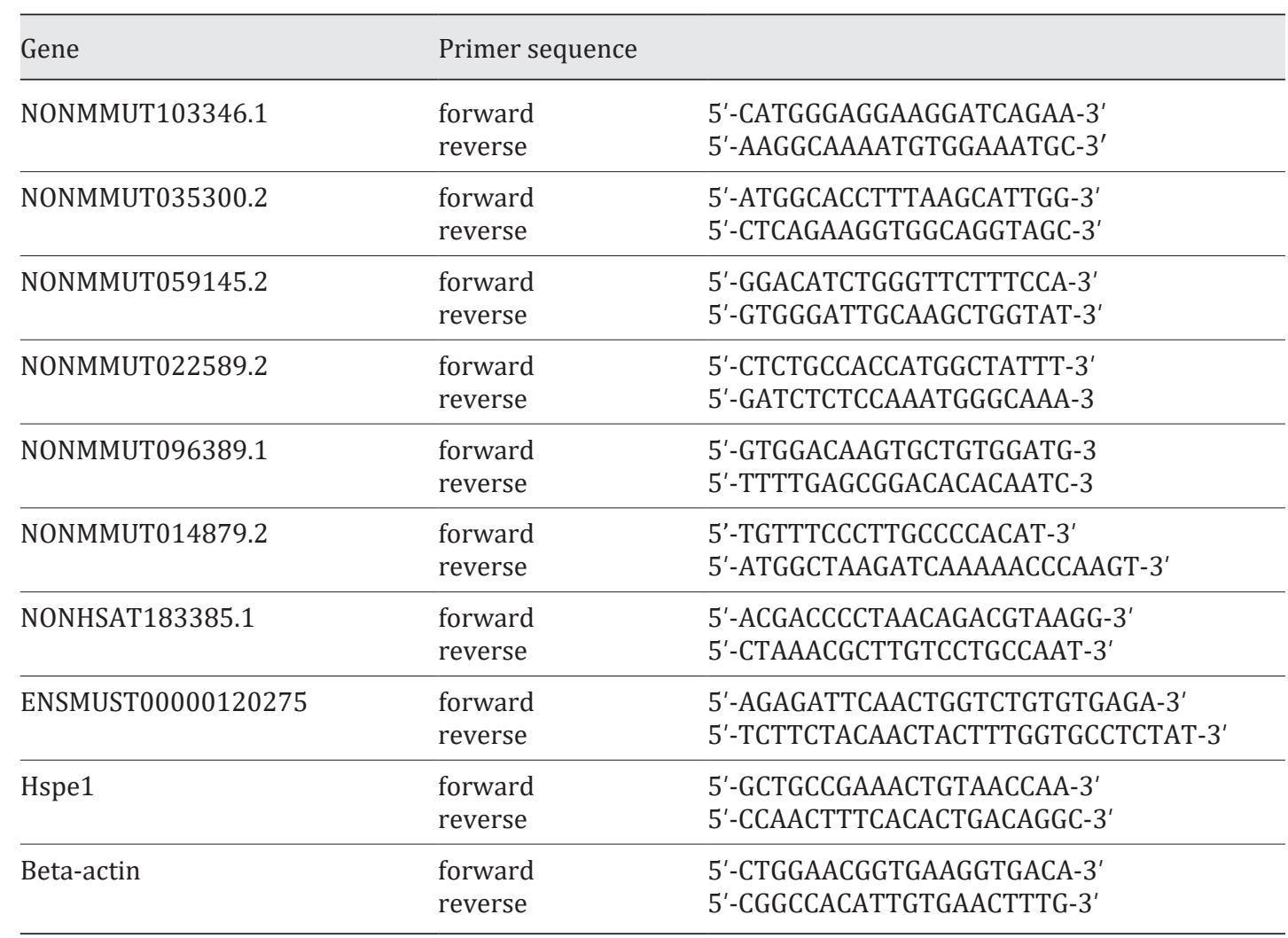

in triplicate, and the specificity of the amplified fragments was checked according to the generated melting curve. Target gene expression was normalized to the expression of $\beta$-actin and all real-time data were analyzed using the comparative CT method $\left(2^{-\Delta \Delta C T}\right)$.

\section{Statistical Analysis}

Data analysis was performed using the SPSS software and results were shown as mean \pm standard deviation. Statistical differences between groups were determined using the Student $t$ test. Analysis of variance was used to determine significant differences among groups. $p$ values $<0.05$ were considered statistically significant.

\section{Results}

Establishment of the Ischemic Injury Model

To confirm the successful establishment of a renal IR injury model in mice, we determined serum creatinine and blood urea nitrogen concentrations. As expected, levels of serum creatinine $(158.9 \pm 17.7 \mu \mathrm{mol} / \mathrm{L})$ were significantly increased in mice subjected to ischemia for $45 \mathrm{~min}$ followed by reperfusion for $24 \mathrm{~h}$ compared to sham-operated mice (43.73 \pm $5.38 \mu \mathrm{mol} / \mathrm{L}$ ). Blood urea nitrogen levels were also observed to be significantly higher in IR injury mice than in sham-operated animals $(57.1 \pm 2.91 \mathrm{mmol} / \mathrm{L}$ vs. $9.7 \pm 0.986 \mathrm{mmol} / \mathrm{L})$ (Fig. 1A, B). Consistent with renal insufficiency, hematoxylin and eosin staining of kidney tissue revealed IR-induced tubular dilatation, epithelial cell disruption and desquamation, brush border loss, and tubular lumen obstruction and congestion (Fig. 1C). 


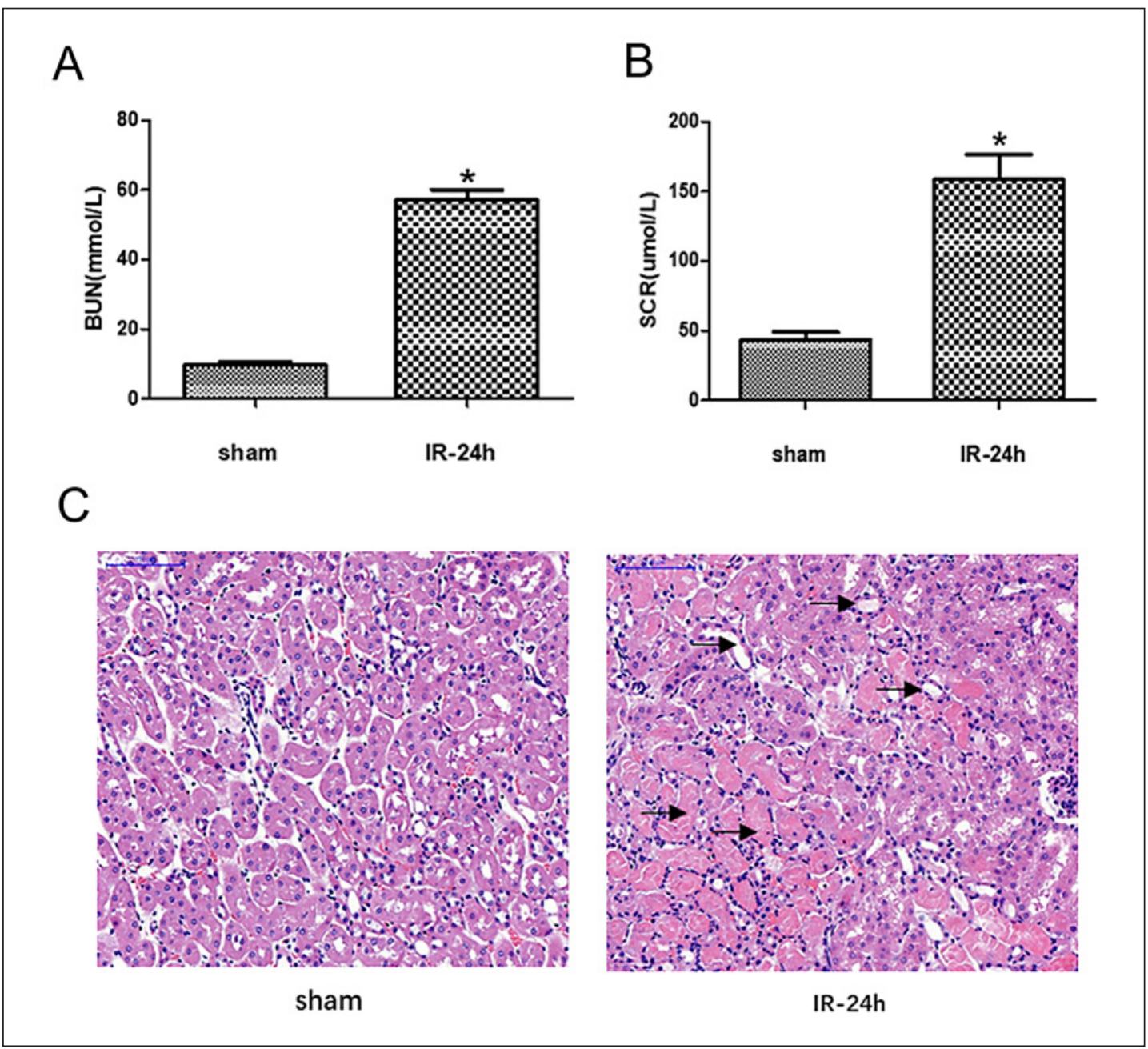

Fig. 1. Functional and histological changes in the kidney after IR injury. A, B Blood urea nitrogen (BUN, A) and serum creatinine (SCR, B) levels of IR $24 \mathrm{~h}$ and sham mice $(n=3)$. C Renal tissue sections were stained with hematoxylin and eosin. Arrows indicate injured tubules. ${ }^{*} p<0.05$ versus sham control. Scale bar, $100 \mu \mathrm{m}$. IR, ischemia-reperfusion.

\section{Differential Gene Expression Characters}

A total of 45,923 lncRNAs were detected in the samples by transcriptome sequencing, and 5,868 distinctly differentially expressed lncRNAs ( $p<0.05$ and fold change $\geq 2$ ) were found in IR $24 \mathrm{~h}$ kidney tissues compared to the expression in control groups, among which 2,908 IncRNAs were observed to be upregulated and 2,960 downregulated (Fig. 2A). To assess the possible function of IncRNA, we performed protein-coding gene sequencing in the same samples and predicted the potential targets of lncRNAs in cis or trans-regulatory relationships. The differentially expressed IncRNAs were predicted to target 5,101 mRNAs, of which 3,052 differentially expressed IncRNAs were predicted to target 1,471 (621 up- and 850 downregulated genes) differentially expressed mRNAs. According to their genomic location, these lncRNAs targeted differential expression of protein-coding genes portioned into 155 bidirectional lncRNAs, 276 exonic antisense lncRNAs, 435 exonic sense lncRNAs, 70 intronic antisense lncRNAs, 835 intronic sense lncRNAs and 1,281 intergenic lncRNAs (Fig. 2C). Renal IR conditions led to the differential expression of 5,160 protein-coding genes (2,384 up- and 2,776 downregulated mRNAs) (Fig. 2B). The above data indicate that approx- 


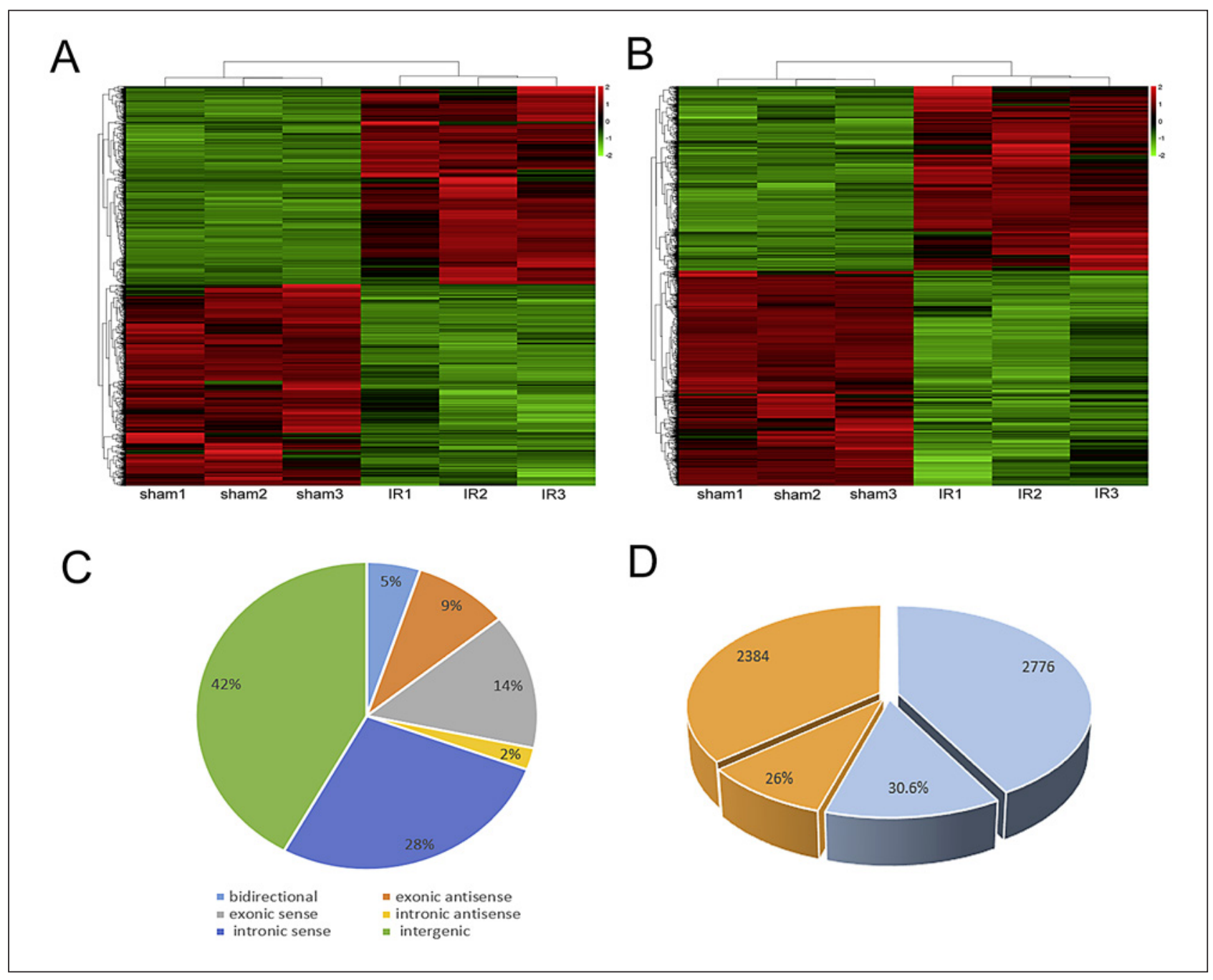

Fig. 2. Features of IncRNA expression. Heatmaps displayed different expression levels of lncRNAs (A) and mRNAs (B) between the control and the IR group. Each column represents a sample and each row represents a lncRNA or mRNA transcript. Red stripes imply high levels of gene expression, while green stripes imply the opposite. C Distribution of IncRNA subtypes. D Distribution of differentially expressed lncRNA-target genes/ differentially expressed protein-coding genes. Orange indicates upregulation of mRNAs after IR $24 \mathrm{~h}$ and gray indicates the opposite. IR, ischemia-reperfusion; lncRNA, long noncoding RNA.

imately $26 \%$ of upregulated mRNA and $30.6 \%$ of downregulated mRNA in mouse renal tissue can be regulated by IncRNA after $24 \mathrm{~h}$ of IR (Fig. 2D).

\section{qRT-PCR Validation}

To confirm the reliability of the RNA sequencing data, we randomly selected seven differentially expressed lncRNAs for validation by qRT-PCR (upexpressed: NONMMUT103346.1, NONMMUT035300.2, NONMMUT059145.2; downexpressed: NONMMUT022589.2, NONMMUT014879.2, NONMMUT096389.1, ENSMUST00000120275). The expression patterns of these lncRNAs validated with qRT-PCR were mostly consistent with lncRNA-Seq results (Fig. 3). 
Kidney

Blood Pressure Research

Fig. 3. Validation of randomly selected differentially expressed IncRNAs for RNA-Seq by quantitative real-time PCR. IncRNAs, long noncoding RNAs.
Kidney Blood Press Res 2020;45:686-701

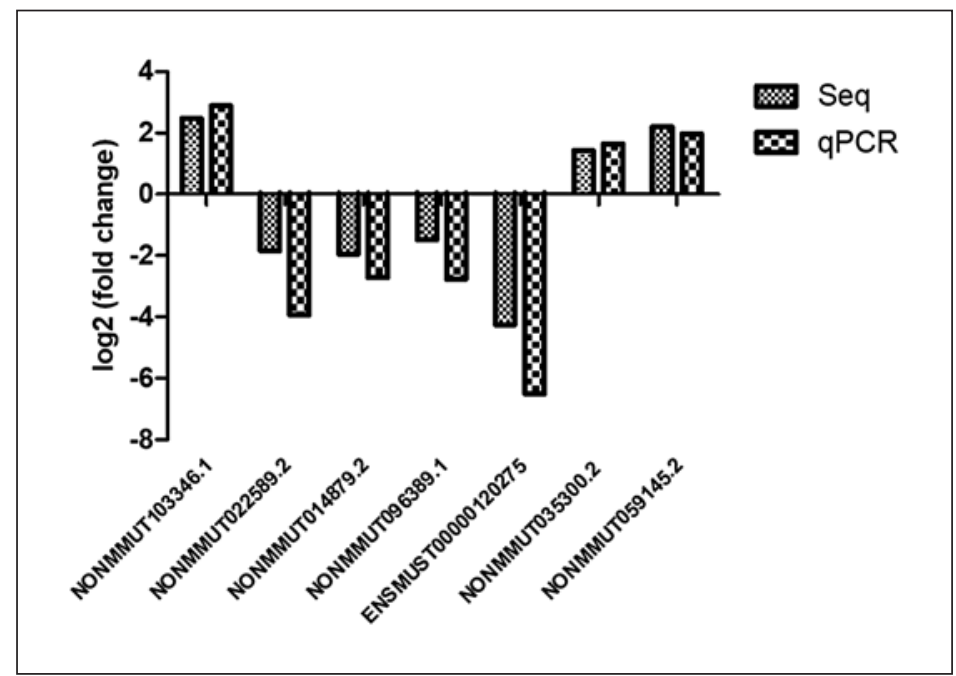

A

GO:1901142 insulin metabolic process GO:0010992 ubiquitin homeostasis GO:0090219 negative regulation of lipid GO:0010994 free ubiquitin chain. GO:1901858 regulation of mitochondrial DNA GO:0046874 quinolinate metabolic process GO:0017196 N-terminal peptidyl-methionine. GO:0090385 phagosome-lysosome fusion GO:0006657 CDP-choline pathway

GO:1903265:positive regulation of tumor. GO:0043553 negative regulation of.

GO:0038089:positive regulation of cell.

GO:0026462 TRAIL-activated apoptotic. GO:0006686 sphingomyelin biosynthetic. GO:0006659 phosphatidylserine biosynthetic

GO:0019563 glycerol catabolic process GO:1900225 regulation of NLRP3 GO:0006269 DNA replication synthesis of GO:2000189 positive regulation of.

C
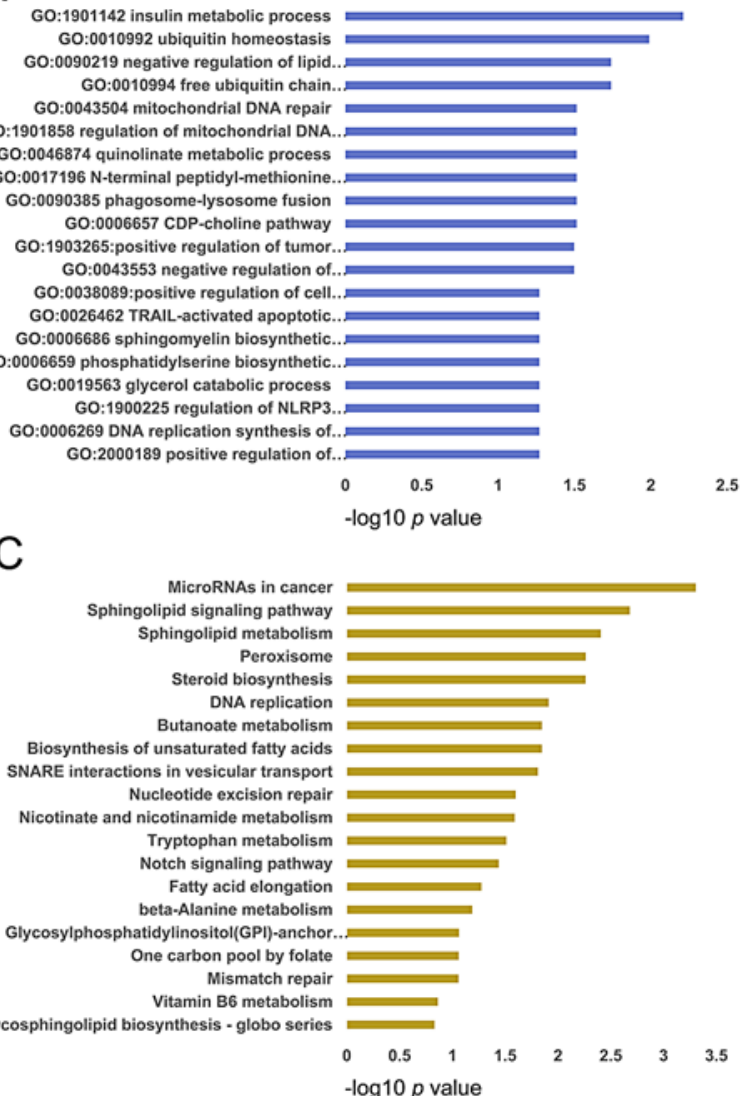

B

GO:0032231 regulation of actin filament.. GO:0050821 protein stabilization GO:0040018 positive regulation of. GO:0090317 negative regulation of.. GO:0006637 acyl-CoA metabolic process G00044773 mitotic DNA damage checkpoint GO:0070527 platelet aggregation GO:0071156 regulation of cell cycle arrest GO:0051881 regulation of mitochondrial... GO:0030032 lamellipodium assembly GO:0044744 mitotic DNA integrity checkpoint GO:0009124 nucleoside monophosphate... GO:0033209 tumor necrosis factor-mediated.

G0:0042308

GO:0070059 intrinsic apoptotic signaling. GO:1900076 regulation of cellular response... GO:0070613 regulation of protein processing

GO:1900181 negative regulation of protein

GO:0090263 positive regulation of canonical. GO:0051492 regulation of stress fiber assembly

D
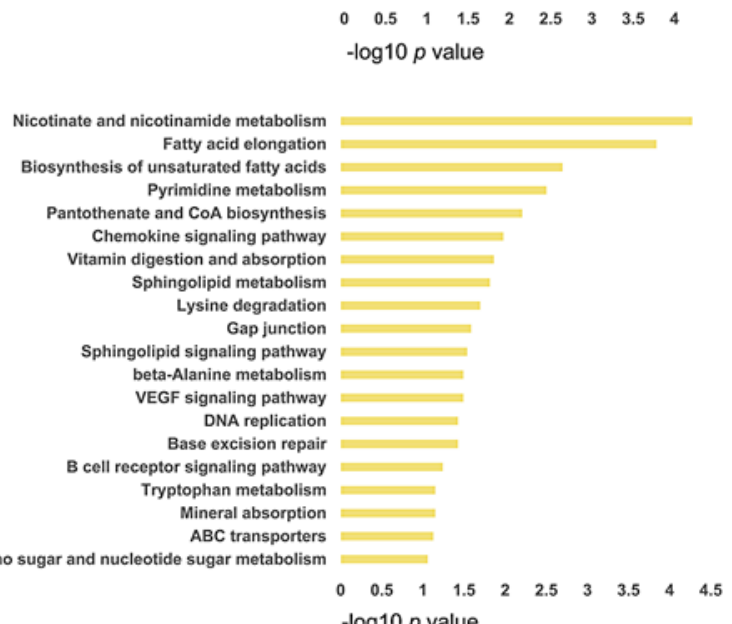

Fig. 4. Functional annotation of IncRNAs. A lncRNA GO BP enrichment (top 20). B Sequence conserved IncRNA GO BP enrichment (top 20). C IncRNA KEGG pathway enrichment (top 20). D Sequence conserved IncRNA KEGG pathway enrichment (top 20). The horizontal axis represents the $p$ value $(-\log 10)$. BP, biological process; GO, Gene Ontology; KEGG, Kyoto Encyclopedia of Genes and Genomes; IncRNA, long noncoding RNA. 
Kidney
Blood Pressure

Research
Kidney Blood Press Res 2020;45:686-701

Table 2. IncRNA sequence alignment results

\begin{tabular}{|c|c|c|c|c|c|c|c|}
\hline Mouse & m-start & m-end & Human & h-start & h-end & Pident & E value \\
\hline MSTRG.28171.1 & 286 & 575 & NONHSAT093240.2 & 1,893 & 1,594 & 88.41 & $2 E-94$ \\
\hline MSTRG.28171.1 & 290 & 575 & NONHSAT196556.1 & 1,890 & 1,595 & 88.59 & $8 E-94$ \\
\hline NONMMUT041012.2 & 1,621 & 1,860 & NONHSAT079881.2 & 2,472 & 2,724 & 81.1 & $2 \mathrm{E}-46$ \\
\hline NONMMUT032806.2 & 888 & 1,526 & NONHSAT107017.2 & 106 & 744 & 87.66 & 0 \\
\hline NONMMUT032806.2 & 944 & 1,017 & NONHSAT107018.2 & 77 & 4 & 91.89 & $9 \mathrm{E}-21$ \\
\hline NONMMUT037264.2 & 595 & 777 & NONHSAT185675.1 & 475 & 293 & 88.52 & $1 \mathrm{E}-56$ \\
\hline NONMMUT022589.2 & 588 & 1,545 & NONHSAT098468.2 & 6,206 & 7,168 & 72.63 & $2 \mathrm{E}-74$ \\
\hline ENSMUST00000131345 & 1,868 & 2,027 & NONHSAT149522.1 & 1 & 160 & 87.5 & $9 E-45$ \\
\hline NONMMUT014994.2 & 1 & 435 & NONHSAT037726.2 & 145 & 579 & 83.6 & $2 \mathrm{E}-111$ \\
\hline NONMMUT014879.2 & 1,734 & 2,141 & NONHSAT183385.1 & 718 & 309 & 82.81 & $2 \mathrm{E}-98$ \\
\hline NONMMUT014879.2 & 1,844 & 2,145 & ENST00000554777 & 296 & 1 & 83.77 & $5 \mathrm{E}-74$ \\
\hline NONMMUT014879.2 & 1,844 & 2,145 & ENST00000559254 & 299 & 1 & 83.11 & $3 \mathrm{E}-71$ \\
\hline NONMMUT014879.2 & 1,834 & 2,136 & ENST00000550617 & 308 & 10 & 82.57 & $2 \mathrm{E}-68$ \\
\hline NONMMUT014879.2 & 1,842 & 2,102 & ENST00000604681 & 316 & 59 & 84.29 & $4 E-65$ \\
\hline NONMMUT014879.2 & 1,846 & 2,091 & ENST00000406997 & 276 & 34 & 83.74 & $2 \mathrm{E}-58$ \\
\hline NONMMUT014879.2 & 1,844 & 2,140 & NONHSAT008913.2 & 287 & 6 & 80.47 & $2 \mathrm{E}-53$ \\
\hline NONMMUT014879.2 & 1,844 & 2,139 & ENST00000479457 & 281 & 1 & 80.41 & $7 E-53$ \\
\hline NONMMUT014879.2 & 1,843 & 2,102 & ENST00000538133 & 284 & 27 & 78.63 & $4 \mathrm{E}-40$ \\
\hline NONMMUT014879.2 & 1,844 & 1,953 & ENST00000426640 & 339 & 233 & 86.36 & $2 \mathrm{E}-24$ \\
\hline NONMMUT028972.2 & 2,472 & 2,596 & NONHSAT163238.1 & 128 & 5 & 82.54 & $1 \mathrm{E}-21$ \\
\hline NONMMUT063900.2 & 131 & 750 & NONHSAT016736.2 & 654 & 36 & 77.22 & $4 E-85$ \\
\hline NONMMUT063900.2 & 874 & 1,070 & NONHSAT156247.1 & 65 & 260 & 83.08 & $8 E-42$ \\
\hline ENSMUST00000180638 & 1,047 & 1,133 & NONHSAT007235.2 & 4,462 & 4,372 & 91.21 & $5 E-26$ \\
\hline NONMMUT015136.2 & 1,959 & 2,284 & NONHSAT217397.1 & 628 & 299 & 85.15 & $6 \mathrm{E}-90$ \\
\hline NONMMUT015136.2 & 1,975 & 2,306 & ENST00000482744 & 335 & 1 & 82.79 & $1 \mathrm{E}-77$ \\
\hline NONMMUT015136.2 & 1,979 & 2,306 & ENST00000429309 & 323 & 1 & 82.83 & $6 \mathrm{E}-75$ \\
\hline NONMMUT015136.2 & 1,979 & 2,244 & ENST00000457129 & 304 & 35 & 84.13 & $1 \mathrm{E}-66$ \\
\hline NONMMUT015136.2 & 2,011 & 2,140 & ENST00000501016 & 920 & 1,052 & 87.97 & $2 \mathrm{E}-35$ \\
\hline ENSMUST00000120275 & 17 & 281 & NONHSAT183385.1 & 340 & 611 & 86.45 & $9 \mathrm{E}-78$ \\
\hline ENSMUST00000120275 & 24 & 280 & ENST00000604681 & 59 & 321 & 84.09 & $5 E-65$ \\
\hline ENSMUST00000120275 & 24 & 273 & ENST00000559254 & 44 & 299 & 84.44 & $2 \mathrm{E}-64$ \\
\hline ENSMUST00000120275 & 17 & 275 & ENST00000339579 & 34 & 298 & 82.4 & $9 E-58$ \\
\hline ENSMUST00000120275 & 25 & 273 & ENST00000479457 & 39 & 281 & 81.64 & $7 E-49$ \\
\hline ENSMUST00000120275 & 25 & 273 & NONHSAT008913.2 & 45 & 287 & 81.64 & $7 E-49$ \\
\hline ENSMUST00000120275 & 24 & 280 & ENST00000421494 & 54 & 315 & 79.92 & $4 E-46$ \\
\hline ENSMUST00000120275 & 17 & 281 & ENST00000605812 & 36 & 301 & 79.42 & $9 E-43$ \\
\hline ENSMUST00000180427 & 1,881 & 2,248 & NONHSAT165747.1 & 568 & 940 & 86.9 & $2 \mathrm{E}-113$ \\
\hline NONMMUT059145.2 & 496 & 798 & NONHSAT184603.1 & 305 & 1 & 84.74 & $3 E-80$ \\
\hline NONMMUT059145.2 & 496 & 664 & NONHSAT070548.2 & 359 & 191 & 83.72 & $6 \mathrm{E}-37$ \\
\hline NONMMUT059145.2 & 225 & 432 & NONHSAT204518.1 & 1,649 & 1,442 & 76.92 & $3 E-25$ \\
\hline ENSMUST00000189634 & 31 & 289 & NONHSAT152317.1 & 2 & 247 & 79.23 & $4 \mathrm{E}-40$ \\
\hline ENSMUST00000189634 & 31 & 289 & NONHSAT152316.1 & 9 & 253 & 78.85 & $2 \mathrm{E}-38$ \\
\hline ENSMUST00000189634 & 46 & 289 & NONHSAT006509.2 & 7 & 240 & 79.27 & $6 \mathrm{E}-38$ \\
\hline ENSMUST00000189634 & 46 & 289 & NONHSAT152318.1 & 97 & 327 & 78.78 & $4 E-35$ \\
\hline NONMMUT033609.2 & 2,945 & 3,877 & NONHSAT022124.2 & 5,990 & 6,966 & 81.97 & 0 \\
\hline NONMMUT033609.2 & 6,024 & 6,142 & NONHSAT022124.2 & 9,647 & 9,774 & 87.5 & $8 \mathrm{E}-31$ \\
\hline NONMMUT033609.2 & 4,480 & 5,861 & NONHSAT022135.2 & 4,433 & 5,824 & 80.19 & 0 \\
\hline NONMMUT033609.2 & 6,024 & 6,142 & NONHSAT022135.2 & 6,016 & 6,143 & 87.5 & $8 \mathrm{E}-31$ \\
\hline NONMMUT033609.2 & 2,945 & 3,877 & NONHSAT022145.2 & 3,198 & 4,174 & 81.97 & 0 \\
\hline NONMMUT033609.2 & 6,024 & 6,142 & NONHSAT022145.2 & 6,736 & 6,863 & 87.5 & $8 \mathrm{E}-31$ \\
\hline NONMMUT033609.2 & 4,480 & 5,861 & NONHSAT022136.2 & 3,972 & 5,363 & 80.19 & 0 \\
\hline NONMMUT033609.2 & 6,024 & 6,142 & NONHSAT022136.2 & 5,555 & 5,682 & 87.5 & 8E-31 \\
\hline NONMMUT033609.2 & 2,945 & 3,877 & ENST00000534336 & 4,495 & 5,471 & 81.97 & 0 \\
\hline NONMMUT033609.2 & 6,024 & 6,142 & ENST00000534336 & 8,152 & 8,279 & 87.5 & $8 E-31$ \\
\hline NONMMUT033609.2 & 3,310 & 3,877 & NONHSAT022132.2 & 3,450 & 4,042 & 82.39 & $9 E-135$ \\
\hline NONMMUT033609.2 & 2,038 & 2,774 & NONHSAT022125.2 & 2,483 & 3,272 & 80.22 & $4 \mathrm{E}-148$ \\
\hline NONMMUT033609.2 & 2,945 & 3,877 & NONHSAT022137.2 & 3,298 & 4,274 & 81.97 & 0 \\
\hline NONMMUT033609.2 & 6,024 & 6,142 & NONHSAT022137.2 & 6,622 & 6,749 & 87.5 & $8 E-31$ \\
\hline
\end{tabular}




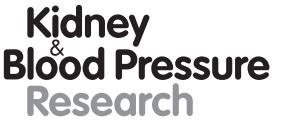

Kidney Blood Press Res 2020;45:686-701

Table 2 (continued)

\begin{tabular}{|c|c|c|c|c|c|c|c|}
\hline Mouse & m-start & m-end & Human & h-start & h-end & Pident & E value \\
\hline NONMMUT033609.2 & 4,480 & 5,861 & NONHSAT022138.2 & 4,565 & 5,956 & 80.19 & 0 \\
\hline NONMMUT033609.2 & 6,024 & 6,142 & NONHSAT022138.2 & 6,148 & 6,275 & 87.5 & $8 \mathrm{E}-31$ \\
\hline NONMMUT033609.2 & 2,038 & 2,557 & NONHSAT022143.2 & 2,173 & 2,722 & 80.82 & $2 \mathrm{E}-106$ \\
\hline NONMMUT033609.2 & 3,310 & 3,877 & NONHSAT022144.2 & 3,339 & 3,931 & 82.39 & 9E-135 \\
\hline NONMMUT033609.2 & 3,310 & 3,765 & NONHSAT022134.2 & 3,440 & 3,920 & 80.82 & $2 \mathrm{E}-92$ \\
\hline NONMMUT033609.2 & 4,480 & 5,813 & NONHSAT022142.2 & 3,902 & 5,238 & 80.42 & 0 \\
\hline NONMMUT033609.2 & 2,945 & 3,877 & NONHSAT022147.2 & 1,367 & 3,91 & 81.97 & 0 \\
\hline NONMMUT033609.2 & 4,480 & 5,403 & NONHSAT022129.2 & 4,684 & 5,599 & 82.27 & 0 \\
\hline NONMMUT033609.2 & 4,480 & 5,403 & NONHSAT022131.2 & 3,267 & 4,182 & 82.27 & 0 \\
\hline NONMMUT033609.2 & 4,480 & 5,403 & NONHSAT022126.2 & 4,767 & 5,682 & 82.27 & 0 \\
\hline NONMMUT033609.2 & 6,024 & 6,142 & NONHSAT022126.2 & 6,125 & 6,252 & 87.5 & $8 \mathrm{E}-31$ \\
\hline NONMMUT033609.2 & 4,480 & 5,196 & NONHSAT022139.2 & 4,792 & 5,483 & 83.13 & $1 \mathrm{E}-173$ \\
\hline NONMMUT033609.2 & 2,038 & 2,774 & NONHSAT022139.2 & 2,216 & 3,005 & 80.22 & $4 \mathrm{E}-148$ \\
\hline NONMMUT033609.2 & 6,024 & 6,142 & NONHSAT022133.2 & 6,380 & 6,507 & 87.5 & $8 \mathrm{E}-31$ \\
\hline NONMMUT033609.2 & 2,945 & 3,314 & NONHSAT022146.2 & 390 & 2 & 81.31 & $2 \mathrm{E}-76$ \\
\hline NONMMUT033609.2 & 2,038 & 2,774 & NONHSAT022130.2 & 1,410 & 621 & 80.22 & $4 \mathrm{E}-148$ \\
\hline NONMMUT033609.2 & 2,945 & 3,300 & NONHSAT022130.2 & 384 & 11 & 81.63 & $3 \mathrm{E}-75$ \\
\hline NONMMUT033609.2 & 3,310 & 3,877 & ENST00000508832 & 550 & 1,142 & 82.39 & 9E-135 \\
\hline NONMMUT033609.2 & 4,480 & 4,981 & ENST00000618132 & 207 & 701 & 84.14 & $3 E-129$ \\
\hline NONMMUT033609.2 & 4,670 & 5,196 & ENST00000610851 & 1 & 503 & 82.31 & $6 \mathrm{E}-117$ \\
\hline NONMMUT033609.2 & 3,305 & 3,765 & NONHSAT159249.1 & 192 & 677 & 80.81 & $1 \mathrm{E}-93$ \\
\hline NONMMUT033609.2 & 5,012 & 5,403 & ENST00000618227 & 11 & 408 & 81.84 & $1 \mathrm{E}-83$ \\
\hline NONMMUT033609.2 & 2,945 & 3,307 & NONHSAT022110.2 & 1,050 & 669 & 81.49 & $8 \mathrm{E}-76$ \\
\hline NONMMUT033609.2 & 3,402 & 3,765 & ENST00000618925 & 1 & 392 & 79.09 & $8 \mathrm{E}-61$ \\
\hline NONMMUT033609.2 & 3,013 & 3,300 & NONHSAT022148.2 & 302 & 5 & 81.58 & $1 \mathrm{E}-58$ \\
\hline NONMMUT033609.2 & 6,024 & 6,109 & NONHSAT159253.1 & 744 & 829 & 95.35 & $3 \mathrm{E}-30$ \\
\hline NONMMUT015894.2 & 1 & 88 & ENST00000554735 & 76 & 162 & 92.05 & $2 \mathrm{E}-26$ \\
\hline NONMMUT015894.2 & 1 & 88 & ENST00000557109 & 68 & 154 & 92.05 & $2 \mathrm{E}-26$ \\
\hline NONMMUT015894.2 & 1 & 89 & ENST00000557661 & 96 & 184 & 91.11 & $6 \mathrm{E}-26$ \\
\hline NONMMUT015894.2 & 1 & 89 & ENST00000554441 & 40 & 128 & 91.11 & $6 \mathrm{E}-26$ \\
\hline NONMMUT015894.2 & 1 & 89 & ENST00000553729 & 57 & 145 & 91.11 & $6 \mathrm{E}-26$ \\
\hline NONMMUT015894.2 & 1 & 87 & ENST00000554694 & 68 & 153 & 91.95 & $6 \mathrm{E}-26$ \\
\hline NONMMUT015894.2 & 1 & 87 & NONHSAT040031.2 & 68 & 153 & 91.95 & $6 \mathrm{E}-26$ \\
\hline NONMMUT015894.2 & 1 & 89 & ENST00000617327 & 13 & 101 & 91.11 & $6 \mathrm{E}-26$ \\
\hline NONMMUT015894.2 & 1 & 87 & ENST00000555174 & 87 & 172 & 91.95 & $6 \mathrm{E}-26$ \\
\hline NONMMUT015894.2 & 1 & 87 & ENST00000557532 & 68 & 153 & 91.95 & $6 \mathrm{E}-26$ \\
\hline NONMMUT012993.2 & 662 & 913 & NONHSAT056324.2 & 300 & 547 & 81.96 & $1 \mathrm{E}-51$ \\
\hline NONMMUT013845.2 & 618 & 765 & NONHSAT212507.1 & 159 & 12 & 93.92 & $4 \mathrm{E}-57$ \\
\hline NONMMUT013845.2 & 620 & 765 & NONHSAT212506.1 & 887 & 742 & 93.84 & $5 \mathrm{E}-56$ \\
\hline NONMMUT005589.2 & 1,799 & 2,136 & NONHSAT032437.2 & 2,424 & 2,769 & 81.3 & $2 \mathrm{E}-69$ \\
\hline NONMMUT001329.2 & 37 & 857 & NONHSAT186261.1 & 510 & 390 & 96.69 & $3 \mathrm{E}-50$ \\
\hline NONMMUT096389.1 & 52 & 745 & NONHSAT163707.1 & 708 & 8 & 85.51 & 0 \\
\hline ENSMUST00000185789 & 44,632 & 45,362 & ENST00000597346 & 47,341 & 48,075 & 91.72 & 0 \\
\hline ENSMUST00000185789 & 32,357 & 32,747 & ENST00000597346 & 34,980 & 35,369 & 86.29 & $1 \mathrm{E}-114$ \\
\hline NONMMUT022058.2 & 1,327 & 1,500 & NONHSAT166937.1 & 787 & 960 & 90.23 & $9 \mathrm{E}-58$ \\
\hline NONMMUT024839.2 & 311 & 938 & NONHSAT163497.1 & 244 & 875 & 87.89 & 0 \\
\hline ENSMUST00000056590 & 31 & 288 & NONHSAT152317.1 & 2 & 247 & 79.54 & $8 \mathrm{E}-42$ \\
\hline ENSMUST00000056590 & 46 & 288 & NONHSAT006509.2 & 7 & 240 & 79.59 & $5 E-39$ \\
\hline ENSMUST00000056590 & 46 & 288 & NONHSAT152318.1 & 97 & 327 & 79.1 & $8 \mathrm{E}-37$ \\
\hline NONMMUT063462.2 & 714 & 1,584 & NONHSAT141042.2 & 1,393 & 2,297 & 85.07 & 0 \\
\hline NONMMUT063462.2 & 1,010 & 1,218 & ENST00000568354 & 383 & 176 & 87.2 & $3 \mathrm{E}-60$ \\
\hline MSTRG.8913.4 & 17,954 & 18,141 & NONHSAT103797.2 & 187 & 1 & 85.42 & $7 \mathrm{E}-46$ \\
\hline MSTRG.8913.4 & 17,998 & 18,193 & ENST00000512933 & 201 & 1 & 82.18 & $1 \mathrm{E}-38$ \\
\hline NONMMUT065808.2 & 1,759 & 2,876 & NONHSAT199361.1 & 55 & 1,175 & 87.13 & 0 \\
\hline NONMMUT035300.2 & 2,886 & 3,164 & NONHSAT016573.2 & 1,894 & 2,178 & 87.76 & $1 \mathrm{E}-87$ \\
\hline NONMMUT011815.2 & 153 & 255 & NONHSAT053356.2 & 2,324 & 2,214 & 90.99 & $3 \mathrm{E}-32$ \\
\hline NONMMUT016470.2 & 1,920 & 2,535 & NONHSAT120258.2 & 1,022 & 1,676 & 84.93 & $2 \mathrm{E}-177$ \\
\hline NONMMUT019025.2 & 119 & 340 & ENST00000603072 & 1 & 218 & 81.17 & $1 \mathrm{E}-42$ \\
\hline NONMMUT016807.2 & 1,508 & 2,484 & NONHSAT108043.2 & 12 & 989 & 91.57 & 0 \\
\hline
\end{tabular}


Kidney
Blood Pressure

Research
Kidney Blood Press Res 2020;45:686-701

(c) 2020 The Author(s). Published by S. Karger AG, Basel www.karger.com/kbr

Liu et al.: Differentially Expressed IncRNA in Renal Ischemia-Reperfusion Injury

Table 2 (continued)

\begin{tabular}{|c|c|c|c|c|c|c|c|}
\hline Mouse & m-start & m-end & Human & h-start & h-end & Pident & E value \\
\hline NONMMUT016807.2 & 2,028 & 2,461 & NONHSAT208863.1 & 466 & 56 & 91.03 & $5 \mathrm{E}-159$ \\
\hline NONMMUT016807.2 & 1,715 & 1,946 & NONHSAT208863.1 & 699 & 468 & 96.98 & $8 \mathrm{E}-107$ \\
\hline NONMMUT103346.1 & 641 & 1,118 & NONHSAT203300.1 & 2,550 & 3,028 & 82.45 & $5 \mathrm{E}-112$ \\
\hline NONMMUT110083.1 & 293 & 584 & NONHSAT189708.1 & 2 & 284 & 85.08 & $5 \mathrm{E}-75$ \\
\hline NONMMUT004318.2 & 2,478 & 2,795 & NONHSAT150492.1 & 1 & 327 & 93.31 & $9 \mathrm{E}-132$ \\
\hline NONMMUT014997.2 & 314 & 757 & NONHSAT037726.2 & 136 & 579 & 83.71 & $9 \mathrm{E}-115$ \\
\hline NONMMUT018006.2 & 1,821 & 2,040 & ENST00000619044 & 1,010 & 1,229 & 77.93 & $2 \mathrm{E}-29$ \\
\hline NONMMUT018006.2 & 1,821 & 2,040 & ENST00000427548 & 1,373 & 1,592 & 77.93 & $2 \mathrm{E}-29$ \\
\hline ENSMUST00000180643 & 3,197 & 3,566 & NONHSAT169452.1 & 289 & 660 & 83.2 & $2 \mathrm{E}-90$ \\
\hline ENSMUST00000180643 & 1,738 & 1,855 & NONHSAT169452.1 & 170 & 287 & 89.83 & $8 \mathrm{E}-35$ \\
\hline ENSMUST00000145410 & 1,202 & 1,406 & NONHSAT196345.1 & 372 & 576 & 96.1 & $7 \mathrm{E}-90$ \\
\hline NONMMUT125899.1 & 1 & 571 & ENST00000537019 & 179 & 788 & 83.71 & $2 \mathrm{E}-151$ \\
\hline NONMMUT040114.2 & 94 & 582 & NONHSAT189325.1 & 14 & 509 & 81.2 & $1 \mathrm{E}-106$ \\
\hline ENSMUST00000185516 & 3,416 & 3,531 & NONHSAT186099.1 & 1 & 119 & 89.08 & $1 \mathrm{E}-32$ \\
\hline NONMMUT009081.2 & 1,059 & 1,307 & NONHSAT184647.1 & 294 & 543 & 82.21 & $5 E-53$ \\
\hline ENSMUST00000176760 & 506 & 858 & NONHSAT163337.1 & 1,792 & 2,144 & 86.69 & $2 \mathrm{E}-107$ \\
\hline ENSMUST00000176760 & 487 & 786 & NONHSAT108187.2 & 495 & 197 & 80.07 & $1 \mathrm{E}-55$ \\
\hline ENSMUST00000176760 & 487 & 786 & NONHSAT108186.2 & 495 & 197 & 80.07 & $1 \mathrm{E}-55$ \\
\hline NONMMUT046485.2 & 2,521 & 3,080 & NONHSAT114055.2 & 6,867 & 7,442 & 78.25 & $2 \mathrm{E}-93$ \\
\hline NONMMUT023603.2 & 369 & 450 & NONHSAT217573.1 & 602 & 682 & 98.78 & $8 \mathrm{E}-33$ \\
\hline NONMMUT023603.2 & 374 & 447 & NONHSAT128599.2 & 71 & 144 & 100 & $1 \mathrm{E}-30$ \\
\hline NONMMUT015630.2 & 4,282 & 4,529 & NONHSAT168911.1 & 316 & 70 & 96.37 & $2 \mathrm{E}-111$ \\
\hline NONMMUT069701.2 & 1,824 & 2,079 & ENST00000558888 & 1,724 & 1,470 & 85.16 & $9 \mathrm{E}-68$ \\
\hline NONMMUT069701.2 & 1,824 & 2,079 & NONHSAT046577.2 & 1,724 & 1,470 & 85.16 & $9 \mathrm{E}-68$ \\
\hline NONMMUT021187.2 & 1 & 253 & ENST00000425586 & 132 & 405 & 82.85 & $2 \mathrm{E}-57$ \\
\hline NONMMUT021187.2 & 49 & 253 & ENST00000621282 & 1 & 226 & 79.2 & 9E-31 \\
\hline NONMMUT021187.2 & 49 & 253 & NONHSAT033777.2 & 1 & 226 & 79.2 & $9 \mathrm{E}-31$ \\
\hline ENSMUST00000128176 & 422 & 622 & NONHSAT176094.1 & 60 & 270 & 89.57 & $3 \mathrm{E}-67$ \\
\hline ENSMUST00000128176 & 1,798 & 1,914 & ENST00000625127 & 1,425 & 1,541 & 95.73 & $4 \mathrm{E}-46$ \\
\hline ENSMUST00000128176 & 1,798 & 1,914 & NONHSAT052946.2 & 933 & 1,049 & 95.73 & $4 \mathrm{E}-46$ \\
\hline ENSMUST00000191701 & 313 & 551 & ENST00000515522 & 189 & 421 & 80.91 & $5 \mathrm{E}-44$ \\
\hline ENSMUST00000172812 & 2,956 & 3,888 & NONHSAT022124.2 & 5,990 & 6,966 & 81.97 & 0 \\
\hline ENSMUST00000172812 & 2,956 & 3,888 & ENST00000534336 & 4,495 & 5,471 & 81.97 & 0 \\
\hline ENSMUST00000172812 & 3,321 & 3,888 & NONHSAT022132.2 & 3,450 & 4,042 & 82.39 & $1 \mathrm{E}-134$ \\
\hline ENSMUST00000172812 & 6,499 & 6,759 & NONHSAT022132.2 & 6,723 & 6,995 & 90.11 & $2 \mathrm{E}-92$ \\
\hline ENSMUST00000172812 & 2,956 & 3,888 & NONHSAT022125.2 & 3,509 & 4,485 & 81.97 & 0 \\
\hline ENSMUST00000172812 & 6,499 & 6,759 & NONHSAT022125.2 & 7,166 & 7,438 & 90.11 & $2 \mathrm{E}-92$ \\
\hline ENSMUST00000172812 & 2,049 & 2,785 & NONHSAT022129.2 & 2,307 & 3,096 & 80.22 & $5 \mathrm{E}-148$ \\
\hline ENSMUST00000172812 & 4,139 & 5,878 & NONHSAT022131.2 & 2,425 & 4,182 & 79.64 & 0 \\
\hline ENSMUST00000172812 & 2,956 & 3,888 & NONHSAT022137.2 & 3,298 & 4,274 & 81.97 & 0 \\
\hline ENSMUST00000172812 & 6,499 & 6,759 & NONHSAT022137.2 & 6,622 & 6,894 & 90.11 & $2 \mathrm{E}-92$ \\
\hline ENSMUST00000172812 & 4,955 & 6,336 & NONHSAT022135.2 & 4,433 & 5,824 & 80.19 & 0 \\
\hline ENSMUST00000172812 & 6,499 & 6,759 & NONHSAT022135.2 & 6,016 & 6,288 & 90.11 & $2 \mathrm{E}-92$ \\
\hline ENSMUST00000172812 & 2,956 & 3,888 & NONHSAT022145.2 & 3,198 & 4,174 & 81.97 & 0 \\
\hline ENSMUST00000172812 & 6,499 & 6,759 & NONHSAT022145.2 & 6,736 & 7,008 & 90.11 & $2 \mathrm{E}-92$ \\
\hline ENSMUST00000172812 & 4,955 & 6,336 & NONHSAT022136.2 & 3,972 & 5,363 & 80.19 & 0 \\
\hline ENSMUST00000172812 & 6,499 & 6,759 & NONHSAT022136.2 & 5,555 & 5,827 & 90.11 & $2 \mathrm{E}-92$ \\
\hline ENSMUST00000172812 & 4,955 & 6,336 & NONHSAT022138.2 & 4,565 & 5,956 & 80.19 & 0 \\
\hline ENSMUST00000172812 & 6,499 & 6,626 & NONHSAT022138.2 & 6,148 & 6,284 & 88.32 & $9 E-36$ \\
\hline ENSMUST00000172812 & 4,955 & 6,288 & NONHSAT022143.2 & 3,886 & 5,222 & 80.42 & 0 \\
\hline ENSMUST00000172812 & 4,955 & 6,288 & NONHSAT022144.2 & 4,910 & 6,246 & 80.42 & 0 \\
\hline ENSMUST00000172812 & 4,955 & 6,288 & NONHSAT022134.2 & 4,403 & 5,739 & 80.42 & 0 \\
\hline ENSMUST00000172812 & 4,377 & 4,696 & NONHSAT022134.2 & 3,918 & 4,235 & 82.53 & $1 \mathrm{E}-69$ \\
\hline ENSMUST00000172812 & 4,955 & 6,288 & NONHSAT022142.2 & 3,902 & 5,238 & 80.42 & 0 \\
\hline ENSMUST00000172812 & 2,049 & 2,769 & NONHSAT022142.2 & 2,173 & 2,946 & 79.82 & $4 \mathrm{E}-139$ \\
\hline ENSMUST00000172812 & 2,956 & 3,888 & NONHSAT022147.2 & 1,367 & 391 & 81.97 & 0 \\
\hline ENSMUST00000172812 & 4,955 & 5,878 & NONHSAT022126.2 & 4,767 & 5,682 & 82.27 & 0 \\
\hline ENSMUST00000172812 & 6,499 & 6,759 & NONHSAT022126.2 & 6,125 & 6,397 & 90.11 & $2 \mathrm{E}-92$ \\
\hline
\end{tabular}




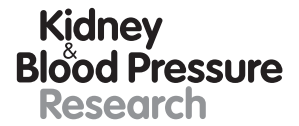

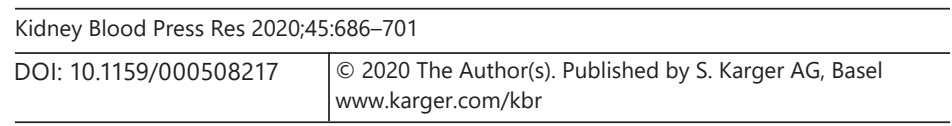

Liu et al.: Differentially Expressed IncRNA in Renal Ischemia-Reperfusion Injury

Table 2 (continued)

\begin{tabular}{|c|c|c|c|c|c|c|c|}
\hline Mouse & m-start & m-end & Human & h-start & h-end & Pident & E value \\
\hline ENSMUST00000172812 & 4,955 & 5,671 & NONHSAT022139.2 & 4,792 & 5,483 & 83.13 & $1 \mathrm{E}-173$ \\
\hline ENSMUST00000172812 & 3,321 & 3,888 & NONHSAT022133.2 & 3,450 & 4,042 & 82.39 & $1 \mathrm{E}-134$ \\
\hline ENSMUST00000172812 & 6,499 & 6,759 & NONHSAT022133.2 & 6,380 & 6,652 & 90.11 & $2 \mathrm{E}-92$ \\
\hline ENSMUST00000172812 & 2,956 & 3,325 & NONHSAT022146.2 & 390 & 2 & 81.31 & $2 \mathrm{E}-76$ \\
\hline ENSMUST00000172812 & 2,049 & 2,785 & NONHSAT022130.2 & 1,410 & 621 & 80.22 & $5 E-148$ \\
\hline ENSMUST00000172812 & 2,956 & 3,311 & NONHSAT022130.2 & 384 & 11 & 81.63 & $3 \mathrm{E}-75$ \\
\hline ENSMUST00000172812 & 3,321 & 3,888 & ENST00000508832 & 550 & 1,142 & 82.39 & $1 \mathrm{E}-134$ \\
\hline ENSMUST00000172812 & 4,955 & 5,456 & ENST00000618132 & 207 & 701 & 84.14 & $4 \mathrm{E}-129$ \\
\hline ENSMUST00000172812 & 5,145 & 5,671 & ENST00000610851 & 1 & 503 & 82.31 & $6 \mathrm{E}-117$ \\
\hline ENSMUST00000172812 & 4,139 & 4,574 & NONHSAT159250.1 & 129 & 572 & 81.58 & $1 \mathrm{E}-93$ \\
\hline ENSMUST00000172812 & 3,316 & 3,776 & NONHSAT159249.1 & 192 & 677 & 80.81 & $1 \mathrm{E}-93$ \\
\hline ENSMUST00000172812 & 4,377 & 4,574 & NONHSAT159249.1 & 675 & 880 & 85.51 & $2 \mathrm{E}-51$ \\
\hline ENSMUST00000172812 & 5,487 & 5,878 & ENST00000618227 & 11 & 408 & 81.84 & $1 \mathrm{E}-83$ \\
\hline ENSMUST00000172812 & 2,956 & 3,318 & NONHSAT022110.2 & 1,050 & 669 & 81.49 & $9 \mathrm{E}-76$ \\
\hline ENSMUST00000172812 & 3,413 & 3,776 & ENST00000618925 & 1 & 392 & 79.09 & $9 \mathrm{E}-61$ \\
\hline ENSMUST00000172812 & 3,024 & 3,311 & NONHSAT022148.2 & 302 & 5 & 81.58 & $1 \mathrm{E}-58$ \\
\hline ENSMUST00000172812 & 6,499 & 6,584 & NONHSAT159253.1 & 744 & 829 & 95.35 & $3 \mathrm{E}-30$ \\
\hline NONMMUT003914.2 & 1 & 117 & NONHSAT163674.1 & 11 & 127 & 91.45 & $4 \mathrm{E}-38$ \\
\hline
\end{tabular}

lncRNA, long noncoding RNA.

\section{Functional Enrichment Analyses of Differentially Expressed IncRNAs}

To understand the potential role of IncRNAs in the development of renal IR injury, we performed Gene Ontology (GO) and Kyoto Encyclopedia of Genes and Genomes (KEGG) pathway enrichment analyses for differentially expressed genes. A total of 1,471 differentially expressed genes with functional annotation information for differentially expressed lncRNAs were assigned to 3,023 G0 terms; 2,347 of the G0 terms significantly enriched for biological process, which are primarily associated with positive regulation of tumor necrosis factor-mediated signaling pathway, cell migration by VEGF signaling pathway, regulation of NLRP3 inflammasome complex assembly, TRAIL-activated apoptotic signaling pathway, and metabolic including ubiquitin, insulin, phospholipid, DNA, quinolinate, etc. (Fig. 4A). Furthermore, KEGG pathway analysis revealed that the differentially expressed genes were found to be mainly enriched in metabolism, SNARE interactions in vesicular transport, peroxisome, microRNAs in cancer, Notch signaling pathway, and sphingolipid signaling pathway (Fig. 4C).

\section{Analysis of Conserved IncRNA}

For searching out the putative human orthologs of differentially expressed mouse lncRNAs in renal IR, 1,135 candidate lncRNAs in mice were compared to lncRNAs in humans through sequence identity. Fifty-six mouse lncRNA transcripts were found to have potential human orthologs (Table 2). While compared to all differentially expressed lncRNAs, the GO biological process terms for conserved lncRNAs tend to be more enriched in the regulation of growth, cell cycle, cytoskeleton organization, platelet aggregation, mitochondrial membrane potential, $\mathrm{TNF} \alpha$-mediated signaling pathway, intrinsic apoptotic signaling pathway, protein stabilization and transport, and Wnt signaling pathway (Fig. 4B). Accordingly, KEGG pathway analyses showed the most significant enrichment of conserved IncRNAs in several novel roles including the VEGF signaling pathway, Gap junction, $A B C$ transporters, the $B$ cell receptor signaling pathway, and the chemokine signaling pathway (Fig. 4D). These results suggest that conserved lncRNAs are closely 
A

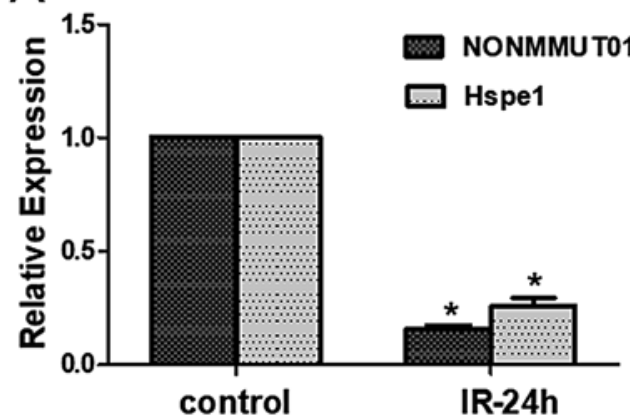

C

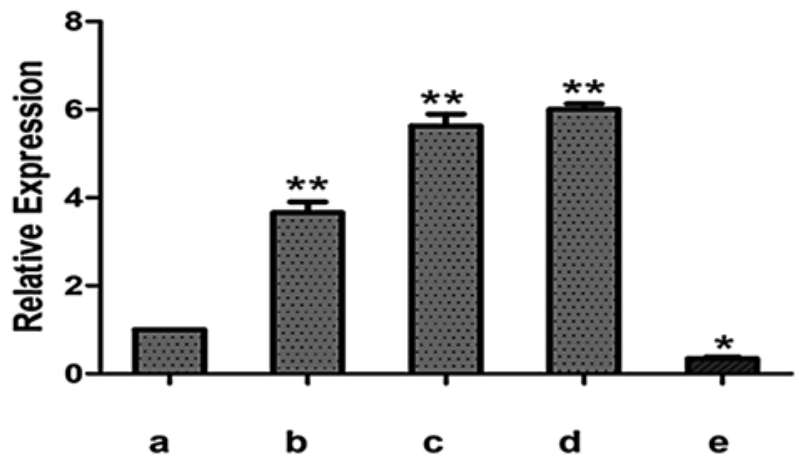

B

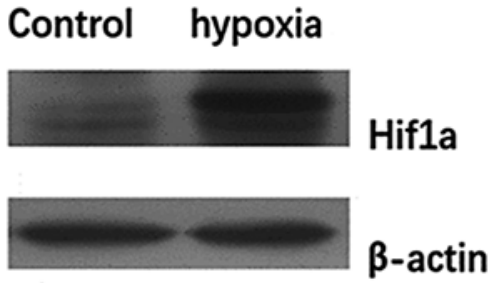

a:control

b:hypoxia24h

c:hypoxia 24h

followed by

reoxyge nation $3 \mathrm{~h}$

d:hypoxia 24h

followed by

reoxygenation $6 \mathrm{~h}$

e:hypoxia $24 \mathrm{~h}$

followed by

reoxyge nation $24 \mathrm{~h}$

Fig. 5. Conserved gene expression levels after IR $24 \mathrm{~h}$ and hypoxia. A The expression of NONMMUT014879.2 and its target Hspe 1, as examined by quantitative real-time PCR, was markedly decreased after IR $24 \mathrm{~h}$, which was consistent with the results of RNA-Seq. B Protein levels of hypoxia-inducible factor $1 \alpha$ (Hif1a) were significantly upregulated in hypoxic HK2 cells. C NONHSAT183385.1 was highly expressed in HK2 cells under hypoxia for $24 \mathrm{~h}$ and further increased after reoxygenation for 3 and $6 \mathrm{~h}$. After $24 \mathrm{~h}$ of reoxygenation, the expression of NONHSAT183385.1 was dramatically downregulated. ${ }^{*} p<0.05$ versus control, ${ }^{* *} p<0.001$ versus control. IR, ischemia-reperfusion.

correlated with the regulation of inflammation, vascular biology, apoptosis, and cell cycle during renal IR injury.

To survey whether these corresponding human IncRNAs with sequence homology have functional homology, we preliminarily observed the expression changes of human IncRNA NONHSAT183385.1 whose mouse counterpart is NONMMUT014879.2 under hypoxia and reoxygenation conditions in vitro. As shown in Figure 5C, the expression of NONHSAT183385.1 was markedly induced in HK2 cells after $24 \mathrm{~h}$ of hypoxia and peaked at $6 \mathrm{~h}$ following restoring normoxic culture. At $24 \mathrm{~h}$ after recovery from normoxia, the expression of NONHSAT183385.1 exhibited a sharp decline. The results suggest that NONHSAT183385.1 may exert an essential action in human renal IR injury. The validation of the expression change of NONMMUT014879.2 and its potential target Hspe1 in renal IR tissues are shown in Figure 5A; the fold changes of NONMMUT014879.2 and Hspe1 were both significantly decreased, which was roughly consistent with the lncRNA-Seq results. 


\section{Kidney \\ Blood Pressure \\ Research}

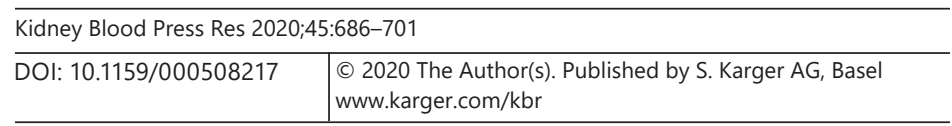

Liu et al.: Differentially Expressed IncRNA in Renal Ischemia-Reperfusion Injury

\section{Discussion}

Renal IR injury is a common clinical disorder characterized by significant additional damage to ischemic tissue after the restoration of blood supply. During reperfusion, cells are exposed to aggravated reactive oxygen, intracellular calcium overload, and inflammatory factor stimulation. Regulation of gene expression is a critical event for cells in response to harmful stress under these pathological conditions. Accumulating evidence has suggested that IncRNAs regulate these pathological processes in renal injury. The lncRNAs MALAT1, TapSAKI, and PVT1 were the most reported lncRNAs involved in the pathogenesis of acute renal injury in humans by modulating inflammation, cell death, and survival [22-24]. However, due to the lack of extensive research, the role of IncRNAs in renal IR injury is still largely unknown.

In the present study, we established a IncRNA expression profile of renal IR injury in mice. It was found that 5,101 mRNAs, including $26 \%$ of the upregulated mRNAs and $30.6 \%$ of the downregulated mRNAs, were the target gene of the differentially expressed IncRNAs by prediction of cis and trans functions. Among a multitude of different signaling pathways induced by renal ischemia injury in mice, these target gene products of differentially expressed lncRNAs tend to primarily function in the regulation of the Notch and sphingolipid signaling pathways. The Notch signaling pathway is a highly conserved intercellular signaling cascade system and crucial for embryogenesis, cellular differentiation, proliferation, and tissue homeostasis in mammals [25]. Previous studies have shown that the Notch signaling pathway is significantly involved in renal IR injury. Gupta et al. [26] found that pretreatment with the Notch ligand DLL4 enhanced recovery from acute renal failure induced by IR in rats. Chen et al.'s study [27] showed that Notch-2 signaling upregulated the expression of survivin in renal proximal tubule epithelial cells, aiding in the functional and structural recovery of the kidney from acute renal injury. Kobayashi et al.'s study [28] suggested that the Delta-1/Notch-2/ Hes-1 signaling pathway may regulate the regeneration and proliferation of renal tubules during acute renal injury. The sphingolipid signaling pathway plays a critical role in IR-induced cellular damage $[29,30]$. The above indicate that lncRNAs may play key regulatory roles in cell survival, apoptosis, and tissue repair in the development of renal IR injury.

Although mice share a high genetic similarity with humans and lots of known human protein-coding genes have functional homologs in mice, most lncRNA transcripts tend to exhibit species specificity and low DNA sequence conservation [31, 32]. Only about $20 \%$ of IncRNA homologous genes were discovered in humans and mice [33], which limits the full understanding of human IncRNAs involved in IR injury by the use of animal models. For all that, it is still of great significance for the functional study of lncRNAs to search for relatively conservative lncRNAs between humans and mice. Conservative lncRNAs often suggest that they may have important biological functions in IR injury. In this work, 56 lncRNAs in the mouse had putative orthologs corresponding to 129 lncRNA transcripts of humans through sequence conservation analysis. It was observed that the conserved IncRNAs in mice were mainly involved in the VEGF signaling pathway, the B cell receptor signaling pathway, and the chemokine signaling pathway, which showed that conserved lncRNAs may play major roles in adjusting kidney microvasculature responses to stress stimuli from ischemia or hypoxia and in regulating the inflammatory cascade after renal IR.

Further, to investigate IncRNA involved in human renal IR injury, we tentatively selected the human IncRNA NONHSAT183385.1, whose mouse counterpart NONMMUT014879.2 had abundant expression based on FPKM expression level in our sequencing results, to perform hypoxic stimulation in vitro for mimicking ischemia in vivo. Since the main pathological feature of renal IR injury is associated with the damage of tubular epithelial cells, which is one of the major functional cells in the kidney, we surveyed the expression changes of the candidate 
human IncRNA in HK2 cells undergoing hypoxia for up to $24 \mathrm{~h}$ followed by restoration of normoxic culture for 3,6 , and $24 \mathrm{~h}$. We found that NONHSAT183385.1 was significantly induced by hypoxia in tubular epithelial cells and dramatically reduced after $24 \mathrm{~h}$ of reoxygenation, which suggested that IncRNA NONHSAT183385.1 may be involved in renal IR injury. According to the trans analysis of our sequencing results, the predicted gene of mouse homologous IncRNA-NONMMUT014879.2 corresponded to NONHSAT183385.1 is Hspe1. Based on our sequence data, Hspe1 expression was markedly decreased after $24 \mathrm{~h}$ of IR as with NONMMUT014879.2. Hspe1 (also known as Hsp10), an important member of the heat shock protein family, is a $10-\mathrm{kDa}$, highly conserved molecular chaperone across species and classically works together with 60-kDa heat shock protein (Hsp60) in folding or driving the degradation of mitochondrial proteins and maintenance of homeostasis in response to adverse stressors [34]. Renal IR injury induces mitochondrial protein misfolding, and disruption of mitochondrial function is the underlying cause of apoptosis in renal tubular epithelial cells. The expression level of Hspe1 is associated with increasing severity of renal IR damage. Whether NONHSAT183385.1 is involved in the progress of human renal IR injury through interaction with the heat shock protein pathway is unclear, and the specific function related to renal IR needs further analysis.

\section{Conclusion}

In summary, the study established a lncRNA expression profile of renal IR injury using a mouse model and conducted a conservative analysis of differentially expressed IncRNAs to hunt their putative human orthologs. Future studies are needed to dissect the role of these homologous human IncRNAs in renal cells. Our work will contribute to reveal important lncRNAs involved in human renal IR injury.

\section{Acknowledgments}

We acknowledge the support by the National Natural Science Foundation of China.

\section{Statement of Ethics}

All animal procedures were conducted after approval by the Animal Committee of Nanchang University (License No. SYXK [Jiangxi] 2015-0001). All experiments were implemented in compliance with the principles of the Institutional Animal Care and Use Committee of Nanchang University.

\section{Conflict of Interest Statement}

The authors have no conflicts of interest to declare.

\section{Funding Sources}

This study was supported by the National Natural Science Foundation of China (grant No. 81560116). 


\section{Kidney \\ Blood Pressure Research}

\begin{tabular}{l|l}
\hline Kidney Blood Press Res 2020;45:686-701 \\
\hline DOI: 10.1159/000508217 & $\begin{array}{l}\text { @ 2020 The Author(s). Published by S. Karger AG, Basel } \\
\text { www.karger.com/kbr }\end{array}$ \\
\hline
\end{tabular}

Liu et al.: Differentially Expressed IncRNA in Renal Ischemia-Reperfusion Injury

\section{Author Contributions}

F. Liu, Y. Yang, T. Liu, J. Deng, H. Zhang, and D. Luo performed the experiments. Y.-L. Lou, F. Liu, and Y. Yang analyzed the data. Y.-L. Lou, F. Liu, and Y. Yang wrote the paper. Y.-L. Lou, F. Liu, and Y. Yang reviewed and edited the manuscript.

\section{References}

1 Bonventre JV, Yang L. Cellular pathophysiology of ischemic acute kidney injury. J Clin Invest. 2011 Nov; 121(11):4210-21.

2 Arai S, Kitada K, Yamazaki T, Takai R, Zhang X, Tsugawa Y, et al. Apoptosis inhibitor of macrophage protein enhances intraluminal debris clearance and ameliorates acute kidney injury in mice. Nat Med. 2016 Feb; 22(2):183-93.

3 Eltzschig HK, Eckle T. Ischemia and reperfusion - from mechanism to translation. Nat Med. 2011 Nov; 17(11): 1391-401.

4 Rinn JL, Chang HY. Genome regulation by long noncoding RNAs. Annu Rev Biochem. 2012;81(1):145-66.

5 Iyer MK, Niknafs YS, Malik R, Singhal U, Sahu A, Hosono Y, et al. The landscape of long noncoding RNAs in the human transcriptome. Nat Genet. 2015 Mar;47(3):199-208.

6 Bánfai B, Jia H, Khatun J, Wood E, Risk B, Gundling WE Jr, et al. Long noncoding RNAs are rarely translated in two human cell lines. Genome Res. 2012 Sep;22(9):1646-57.

7 Makarewich CA, Olson EN. Mining for Micropeptides. Trends Cell Biol. 2017 Sep;27(9):685-96.

8 Ma L, Bajic VB, Zhang Z. On the classification of long non-coding RNAs. RNA Biol. 2013 Jun;10(6):925-33.

9 Wang KC, Chang HY. Molecular mechanisms of long noncoding RNAs. Mol Cell. 2011 Sep;43(6):904-14.

10 Mercer TR, Mattick JS. Structure and function of long noncoding RNAs in epigenetic regulation. Nat Struct Mol Biol. 2013 Mar;20(3):300-7.

11 Mercer TR, Dinger ME, Mattick JS. Long non-coding RNAs: insights into functions. Nat Rev Genet. 2009 Mar; 10(3):155-9.

12 Geisler S, Coller J. RNA in unexpected places: long non-coding RNA functions in diverse cellular contexts. Nat Rev Mol Cell Biol. 2013 Nov;14(11):699-712.

13 Guttman M, Donaghey J, Carey BW, Garber M, Grenier JK, Munson G, et al. lincRNAs act in the circuitry controlling pluripotency and differentiation. Nature. 2011 Aug;477(7364):295-300.

14 Li J, Xuan Z, Liu C. Long non-coding RNAs and complex human diseases. Int J Mol Sci. 2013 Sep;14(9):18790808.

15 Chen X, Yan CC, Zhang X, You ZH. Long non-coding RNAs and complex diseases: from experimental results to computational models. Brief Bioinform. 2017 Jul;18(4):558-76.

16 Shi X, Sun M, Liu H, Yao Y, Song Y. Long non-coding RNAs: a new frontier in the study of human diseases. Cancer Lett. 2013 Oct;339(2):159-66.

17 Liao K, Xu J, Yang W, You X, Zhong Q, Wang X. The research progress of LncRNA involved in the regulation of inflammatory diseases. Mol Immunol. 2018 Sep;101:182-8.

18 Lorenzen JM, Thum T. Long noncoding RNAs in kidney and cardiovascular diseases. Nat Rev Nephrol. 2016 Jun;12(6):360-73.

19 Lin J, Zhang X, Xue C, Zhang H, Shashaty MG, Gosai SJ, et al. The long noncoding RNA landscape in hypoxic and inflammatory renal epithelial injury. Am J Physiol Renal Physiol. 2015 Dec;309(11):F901-13.

20 Mimura I, Hirakawa Y, Kanki Y, Kushida N, Nakaki R, Suzuki Y, et al. Novel lnc RNA regulated by HIF-1 inhibits apoptotic cell death in the renal tubular epithelial cells under hypoxia. Physiol Rep. 2017 Apr;5(8):e13203.

21 Li J, Gong Q, Zhong S, Wang L, Guo H, Xiang Y, et al. Neutralization of the extracellular HMGB1 released by ischaemic damaged renal cells protects against renal ischaemia-reperfusion injury. Nephrol Dial Transplant. 2011 Feb;26(2):469-78.

22 Kölling M, Genschel C, Kaucsar T, Hübner A, Rong S, Schmitt R, et al. Hypoxia-induced long non-coding RNA Malat1 is dispensable for renal ischemia/reperfusion-injury. Sci Rep. 2018 Feb;8(1):3438-3421.

23 Lorenzen JM, Schauerte C, Kielstein JT, Hübner A, Martino F, Fiedler J, et al. Circulating long noncoding RNA TapSaki is a predictor of mortality in critically ill patients with acute kidney injury. Clin Chem. 2015 Jan;61(1): 191-201.

24 Huang W, Lan X, Li X, Wang D, Sun Y, Wang Q, et al. Long non-coding RNA PVT1 promote LPS-induced septic acute kidney injury by regulating TNF $\alpha$ and JNK/NF- $\mathrm{BB}$ pathways in HK-2 cells. Int Immunopharmacol. 2017 Jun;47:134-40.

25 Siebel C, Lendahl U. Notch Signaling in Development, Tissue Homeostasis, and Disease. Physiol Rev. 2017 Oct; 97(4):1235-94.

26 Gupta S, Li S, Abedin MJ, Wang L, Schneider E, Najafian B, et al. Effect of Notch activation on the regenerative response to acute renal failure. Am J Physiol Renal Physiol. 2010 Jan;298(1):F209-15.

27 Chen J, Chen JK, Conway EM, Harris RC. Survivin mediates renal proximal tubule recovery from AKI. J Am Soc Nephrol. 2013 Dec;24(12):2023-33. 
28 Kobayashi T, Terada Y, Kuwana H, Tanaka H, Okado T, Kuwahara M, et al. Expression and function of the Delta-1/Notch-2/Hes-1 pathway during experimental acute kidney injury. Kidney Int. 2008 Jun;73(11): 1240-50.

29 Molino S, Tate E, McKillop WM, Medin JA. Sphingolipid pathway enzymes modulate cell fate and immune responses. Immunotherapy. 2017 Nov;9(14):1185-98.

30 Shupik MA, Vanin AF, Alessenko AV. Interaction of the nitric oxide signaling system with the sphingomyelin cycle and peroxidation on transmission of toxic signal of tumor necrosis factor- $\alpha$ in ischemia-reperfusion. Biochemistry (Mosc). 2011 Nov; 76(11):1197-209.

31 Johnsson P, Lipovich L, Grandér D, Morris KV. Evolutionary conservation of long non-coding RNAs; sequence, structure, function. Biochim Biophys Acta. 2014 Mar;1840(3):1063-71.

32 Bu D, Luo H, Jiao F, Fang S, Tan C, Liu Z, et al. Evolutionary annotation of conserved long non-coding RNAs in major mammalian species. Sci China Life Sci. 2015 Aug;58(8):787-98.

33 Hezroni H, Koppstein D, Schwartz MG, Avrutin A, Bartel DP, Ulitsky I. Principles of long noncoding RNA evolution derived from direct comparison of transcriptomes in 17 species. Cell Rep. 2015 May;11(7):111022.

34 Zhao Q, Wang J, Levichkin IV, Stasinopoulos S, Ryan MT, Hoogenraad NJ. A mitochondrial specific stress response in mammalian cells. EMBO J. 2002 Sep;21(17):4411-9. 